\title{
REAÇÃO DE GENÓTIPOS DE MARACUJAZEIRO-AMARELO AO Colletotrichum gloeosporioides ${ }^{1}$
}

\author{
IRENE MARTINS ${ }^{2}$, JOSÉ RICARDO PEIXOTO³, NILTON VILELA TADEU JUNQUEIRA4 ${ }^{4}$, \\ SUELICORREAA MARQUES DE MELLO
}

RESUMO - O presente trabalho foi desenvolvido em casa de vegetação, na Estação Biológica da Universidade de Brasília, com objetivo de avaliar genótipos de maracujazeiro-amarelo frente ao fungo $C$. gloeosporioides, agente causal da antracnose. Para inoculação dos genótipos, utilizou-se uma suspensão contendo $5 \times 10^{6}$ esporos $/ \mathrm{mL}$ do patógeno, depositados sobre ferimentos preestabelecidos com auxílio de escova de aço de cerdas finas. A primeira avaliação foi realizada 20 dias após a inoculação, e as demais, a intervalos de 7 dias, encerrando-se na sétima avaliação, aos 62 dias. Determinaram-se a incidência e a severidade da antracnose, com auxílio de uma escala graduada de notas, onde $1=$ ausência de sintomas e $7=$ desfolha. Consideraram-se as plantas como: Resistentes (R), com notas médias $\leq 2$; Moderadamente Resistentes (MR), com notas médias $>2$ e $\leq 3$; Suscetíveis (S), com notas médias $>3$ e $\leq 4$; e Altamente Suscetíveis (AS), com notas médias $>4$. No geral, dois genótipos foram classificadas como Moderadamente Resistentes; oito, como Suscetíveis e 62, como Altamente Suscetíveis.

Termos para Indexação: antracnose, resistência, Passiflora edulis Sims f. flavicarpa.

\section{REACTION OF SOUR PASSIONFRUIT GENOTYPES TO Colletotrichum gloeosporioides}

ABSTRACT - The present work was carried out in order to evaluate the resistance of passion fruit genotypes to C. gloeosporioides, the agent of anthracnose. C. gloeosporioides was inoculated in the lineages of passion fruit plants at a concentration of $5 \times 10^{6}$ spores on wounds pre-established by abrasion with a fine steel brush. The first evaluation was carried out 20 days after the inoculation and the others in intervals of seven days, ending in the seventh evaluation 62 days after the inoculation. To evaluate the degree of incidence and severity of anthracnose, a grade scale was established, where $1=$ absence of symptoms and $7=$ leaf loss. Average grades $<2=$ Resistant (R); $>2$ and $\leq 3=$ Moderately Resistant (MR); $>3$ and $\leq 4=$ Susceptible (S) and $>=$ Highly Susceptible (HS). In general, two genotypes were classified as Moderately Resistant; eight as Susceptible and sixty-two were highly Susceptible. Index Terms: anthracnose, resistance, Passiflora edulis Sims f. flavicarpa.

\section{INTRODUÇÃO}

A cultura do maracujazeiro-amarelo (Passiflora edulis Sims f. flavicarpa Degener) vem sofrendo, no Brasil, grandes prejuízos ocasionados por doenças, especialmente a antracnose, causada pelo fungo Colletotrichum gloeosporioides (Penzig) Saccardo (Teleomorfo: Glomerella cingulata) (Stoneman) Spaulding \& Schrenk (Santos Filho \& Santos, 2003; Almeida, 2005; Fischer et al., 2005). Essa doença, conhecida no País desde o início da década de 1970 (Francisco Neto et al., 1995; Miranda, 2004), encontra-se largamente disseminada em todas as regiões produtoras dos diversos países que exploram a cultura (Junqueira et al., 2005; Todafuta, 2006). Sua maior ocorrência tem sido nos países tropicais e subtropicais (Santos Filho et al., 2004) onde, sob condições de temperatura e umidade elevada, causam danos tanto na fase de desenvolvimento da planta como na pós-colheita, incidindo em todos os órgãos aéreos da planta. É uma doença controlada apenas com o uso de fungicidas. Há necessidade de se encontrar métodos alternativos de controle. Cunha et al. (2004) e Meletti et al. (2005) destacam o uso de cultivares resistentes como medida estratégica para a redução dos custos de produção, melhoria da qualidade do produto, sustentabilidade do agronegócio e, principalmente, preservação do meio ambiente.

Há poucos estudos relacionados à resistência de genótipos de maracujazeiro à antracnose. Diante dos fatos mencionados, este trabalho objetivou selecionar genótipos de maracujazeiro-amarelo resultantes de cruzamento inter e intraespecífico que possam ser utilizados como fonte de resistência ao fungo C. gloeosporioides.

\footnotetext{
'(Trabalho 219/2007). Parte da dissertação da primeira autora apresentada a Universidade de Brasília/FAV como requisito para obtenção do título de mestre em Ciências Agrárias.

${ }^{2}$ Bióloga, MSc em agronomia. Embrapa/Cenargen. Caixa Postal 02372. CEP: 70770-900, Brasília-DF. E-mail: irene@cenargen.embrapa.br

${ }^{3}$ Eng. Agr., PhD, Universidade de Brasília, FAV. E-mail: peixoto@unb.br

${ }^{4}$ Eng. Agr., PhD, Embrapa Cerrados. Caixa Postal 08223. CEP: 73301-970 Brasília-DF. E-mail: junqeir@cpac.embrapa.br

${ }^{5}$ Eng. Agr., PhD, Embrapa/Cenargen. Caixa Postal 02372. CEP: 70770-900 Brasília-DF. E-mail: smello@cenargen.embrapa.br
} 


\section{MATERIAL E MÉTODOS}

O experimento foi conduzido em casa de vegetação localizada na Estação Experimental de Biologia - Universidade de Brasília-DF, onde a temperatura variou entre 10 e $30^{\circ} \mathrm{C}$, e a umidade relativa do ar, entre 60 a $100 \%$.

O delineamento experimental utilizado foi o de blocos casualizados, com quatro repetições e seis plantas por parcela, em esquema de parcelas subdivididas, sendo sete épocas de avaliação na parcela e 72 genótipos na subparcela.

Os genótipos avaliados foram oriundos de plantas provenientes de sementes de 72 genótipos, dos quais, 53 foram obtidos por meio de seleção massal, a partir de plantios comerciais, contendo nove genótipos superiores [(Maguary Mesa 1, Maguary Mesa 2, Havaiano, Marília Seleção Cerrado (MSC), Seleção DF, EC-2-O, $\mathrm{F}_{1}$ (Marília x Roxo Australiano), $\mathrm{F}_{1}$ (Roxo Fiji x Marília) e $\mathrm{RC}_{1}\left[\mathrm{~F}_{1}\right.$ (Marília x Roxo Australiano) $\mathrm{x}$ Marília (pai recorrente)]. Nesta seleção, obtiveram-se os seguintes genótipos: MAR 20-01, MAR 20-03, MAR 20-04, MAR 20-05, MAR 20-06, MAR.20-07, MAR.20-08, MAR 20-09, MAR 20-11, MAR 20-13, MAR 20-14, MAR 20-15, MAR 20-16, MAR 20-17, MAR 20-19, MAR 20-20, MAR 20-21, MAR.20-22, MAR 20 23, MAR 20-24, MAR 20-25, MAR 20-26, MAR 20-27, MAR 20-28, MAR 20-29, MAR 20-30, MAR 20-31, MAR 20-32, MAR 20-33, MAR 20-34, MAR 20-35, MAR 20-36, MAR 20-37, MAR 20-38, MAR 20-39, MAR 20-40, MAR 20-41, MAR 20-43, MAR 20-44, MAR 20-45, MAR 20-46, MAR 20-47, MAR 20-48, MAR 20-49, MAR 20-50, Roxo Médio, Roxo Australiano Polycross, Amarelo Arredondado, Roxo Escuro Alongado, Roxo Médio Alongado, Rosa Claro, Amarelo Alongado e Roxo Claro.

Os 19 genótipos restantes foram obtidos pela Embrapa Cerrados, por meio de cruzamentos e retrocruzamentos intra e interespecíficos: Rubi Gigante, resultado do cruzamento entre Roxo Australiano x Marília; Redondão, genótipo comercial introduzido de Porto Rico em 1998; EC-3-0, híbrido ( $\mathrm{RC}_{1}$ ) de polinização controlada entre os genótipos Marília x Roxo Australiano e retrocruzado com Marília, ou seja, $\mathrm{F}_{1}$ x Marília; ECL-7, derivado do genótipo Marília; Maguary FB 100 e Yellow Master FB 200 (Seleção de Flora Brasil), ambos genótipos comerciais suscetíveis à septoriose (Septoria passiflorae), incluídos como testemunhas; PES-09 e PES-07, representantes da geração $\left(\mathrm{F}_{3}\right)$ obtida por polinização controlada entre as espécies P. edulis x P. setacea D.C; GA-2, resultante do cruzamento dos genótipos Sul Brasil x Redondão; Vermelhinho [(P. caerulea Linnaeus x P. edulis f. flavicarpa) x Marília]; AR-1, obtido do cruzamento entre GA-2 x MA (matriz derivada do genótipo Redondão); Maracujá Moranga (Seleção de material introduzido de Porto Rico em 1996); Gigante Amarelo, resultante do cruzamento entre o genótipo Redondão x MSC; AP-1, obtido do cruzamento entre tipos de maracujá-amarelo de alta produtividade, selecionados em pomar comercial; AR-2, genótipo híbrido obtido do cruzamento do "Redondão" pela seleção de maracujá-amarelo, considerado resistente a doenças de raízes e de parte aérea; GA2 x Rubi híbrido; genótipos 07 RC-3; PES-3 e 20/205.
Os isolados de C. gloeosporioides foram obtidos a partir de folhas e frutos coletados em supermercados e pomares no DF. O material, apresentando sintomas típicos da antracnose (lesões coalescentes), foi levado ao laboratório, onde se efetuou o isolamento, utilizando-se das técnicas descritas por Amorim \& Salgado (1995).

Para a caracterização dos isolados, foram utilizados parâmetros indicados por von Arx (1957), Sutton (1980 e 1992), tais como: aspecto da colônia, tamanho e forma dos conídios, presença ou ausência de setas, assim como formação de apressórios.

Quatro isolados, sendo três obtidos de folhas e frutos de maracujazeiros procedentes do Distrito Federal (CEN 419, CEN 421, CEN 433), e um cedido pela UFRPE (CEN 422) foram testados quanto à patogenicidade, utilizando-se de maracujazeiros (genótipos Yellow Master FB 100 e MAR 20-13), com 40 dias de idade, como plantas-teste. Com base nesse teste, selecionou-se o isolado CEN 419 para uso nos ensaios.

As plantas usadas nos ensaios foram cultivadas em bandejas de poliestireno extendido de 72 células (capacidade de $120 \mathrm{~mL} /$ célula), contendo substrato à base de casca de Pínus e vermiculita (Plantmax ${ }^{\circledR}$ ). Foram colocadas quatro sementes por célula. Trinta e dois dias após a semeadura, as mudas foram repicadas para outras bandejas de poliestireno, mantendo-se uma muda por célula. Aos 51 e 61 dias da repicagem, as plantas receberam adubações de cobertura com sulfato de amônia $(0,1 \mathrm{~g} /$ planta).

As inoculações foram realizadas quando as plantas se encontravam com 80 dias ( 7 a 9 folhas), por aspersão de uma suspensão contendo $5 \times 10^{6}$ conídios $/ \mathrm{mL}$ sobre as faces abacial e adaxial das folhas medianas, previamente perfuradas com uma escova de cerdas de aço fino. Os conídios foram produzidos em meio líquido (Batata-dextrose) e extraídos por centrifugação (10.000 rpm por 10 minutos), seguida de ressuspensão da parte sólida em água estéril. A concentração final foi ajustada com auxílio de câmara de Neubauer. Utilizaram-se $150 \mathrm{~mL}$ da suspensão de inóculo por bandeja. As plantas inoculadas foram mantidas em câmara úmida até o final do experimento. A umidade na câmara foi mantida por meio de nebulizações programadas durante 10 minutos por hora. Foram também fornecidos cerca de $50 \mathrm{~mL}$ de água por planta, diariamente, para complementar a irrigação.

Entre as folhas feridas, escolheram-se três localizadas na região central da planta (folhas de idade média) para serem avaliadas.

Foram realizadas sete avaliações de severidade, utilizando uma escala de notas ( 1 a 7), levando-se em consideração a porcentagem de área foliar lesionada infectada, como a seguir:

1 - Ausência de sintomas.

2 - De 1 a $10 \%$ da área lesionada.

3 - De 10 a $25 \%$ da área lesionada.

4 - De 25 a $50 \%$ da área lesionada.

5 - De 50 a $100 \%$ da área lesionada.

6 - Rompimento do tecido necrosado.

7- Desfolha parcial.

Com base nessa escala, as plantas foram classificadas em: Resistentes (R)-notas médias $\leq 2$; Moderadamente Resistentes 
(MR)-notas médias $>2 \mathrm{e} \leq 3$; Suscetíveis (S)-notas médias $>3 \mathrm{e}$ $\leq 4$, e Altamente Suscetíveis (AS)-notas médias $>4$.

A incidência da antracnose foi determinada com base na porcentagem de plantas com sintomas, sendo feita a primeira leitura aos 20 dias após a inoculação, e as demais, em intervalos de sete dias.

Os dados coletados foram submetidos à análise de variância (ANOVA) e teste de F, e as médias, comparadas pelo teste de Tukey, ao nível de 5\% de significância, utilizando-se do programa SANEST (Zonta \& Machado, 1995).

\section{RESULTADOS E DISCUSSÃO}

Os resultados obtidos mostraram diferença significativa entre as épocas de avaliação, tanto para a severidade da doença (nota) quanto para a incidência (\%) de plantas infectadas. A severidade máxima ocorreu na última época de avaliação $\left(7^{\mathrm{a}}\right)$, enquanto a incidência atingiu o valor máximo a partir da $3^{\text {a }}$ avaliação, permanecendo até a ultima avaliação.

Os genótipos PES-7 e PES-9 diferiram dos demais quanto à incidência (\%) e severidade (nota) da antracnose (Tabela 1). Na testemunha, onde foi aspergida apenas água destilada estéril, não ocorreu o desenvolvimento de lesões. Nenhum dos genótipos avaliados apresentou resistência à antracnose, mas houve diferença significativa entre eles, pelo teste de Tukey a $5 \%$.

Resultados semelhantes foram encontrados por Junqueira et al. (2003), em trabalho realizado com 11 genótipos de maracujazeiro-amarelo de propagação sexuada, em campo, sem uso de agrotóxicos e com inóculo natural, relacionado à reação de genótipos de maracujazeiro a diferentes doenças. Esses autores observaram que, quanto à reação dos genótipos à antracnose do fruto, foram observadas diferenças significativas entre eles, no entanto nenhum apresentou resistência completa. Os genótipos Redondão e EC-3-0 foram classificados por eles como moderadamente resistentes, e, neste trabalho, o genótipo Redondão foi classificado como suscetível, e EC-3-0 como altamente suscetível.

Miranda (2004) avaliou 15 genótipos de maracujazeiroamarelo de propagação sexuada, sem aplicação de agrotóxicos e sob condições de campo (inóculo natural), em frutos, e classificou 14 genótipos como moderadamente resistentes e um (MAR 2036) como resistente à antracnose. Quatorze desses foram, no presente trabalho, classificados da seguinte forma: suscetíveis - MAR 20-16 e MAR 20-30 e altamente suscetíveis - MAR 2021, MAR 20-38, MAR 20-15, MAR 20-04, MAR 20-31, MAR 2036, MAR 20-32, MAR 20-22, MAR 20-06, MAR 20-35, MAR 2008 e MAR 20-13. Os resultados obtidos foram muito próximos, apesar da diferença entre as duas metodologias de avaliação adotadas (fruto e folhas).

Sousa (2005), com base na avaliação da resistência em frutos, trabalhando com 17 genótipos propagados sexualmente, em campo (inóculo natural), e sem o uso de agrotóxicos, classificou-os como resistentes à antracnose. Destes, 13 foram no presente trabalho, classificados da seguinte forma: Redondão e Rubi Gigante como suscetíveis; FB 100, Gigante Amarelo, Maracujá Moranga, Vermelhinho, EC-3-0, MAR 20-03, MAR 2004, MAR 20-09, MAR 20-15, FB 200 e EC-7-L como altamente suscetíveis.

É oportuno destacar algumas diferenças básicas na avaliação do presente trabalho, desenvolvido sob ambiente protegido, com os trabalhos desenvolvidos por Junqueira et al. (2003), Miranda (2004) e Sousa (2005), em campo. Entre outras diferenças, cita-se o fato de ter sido usado inóculo artificial neste trabalho e inóculo natural no campo aberto. O estado vegetativo das plantas sendo mudas, neste trabalho, e plantas adultas no campo. As partes vegetativas utilizadas para avaliar a severidade da doença sendo folhas, neste trabalho, e frutos no campo. Neste trabalho, foi utilizada, além da irrigação, nebulização, enquanto no campo foi utilizada somente irrigação. E, finalmente, deve-se levar em consideração o fator variação dentro do genótipo.

Mesmo com alto índice de desfolha, a mortalidade de plantas foi baixa, mostrando que não houve disseminação da doença na planta, ficando restrita às folhas lesionadas. Apesar de não ter ocorrido genótipo resistente, houve seleção individual de plantas dentro de genótipo pelo fato de estarem segregando, ou seja, houve uma acentuada variação dentro de cada genótipo, sendo constatada a presença de plantas resistentes e moderadamente resistentes mesmo após um longo período de tempo (62 dias após inoculação).Esse fato deve ser considerado no programa de melhoramento. Esse é um fator positivo, pois facilita o manejo integrado do patógeno.

As variedades comerciais Maguary FB100 e Yellow Master FB200 foram utilizadas neste trabalho como testemunhas suscetíveis e foram classificadas como altamente suscetíveis à antracnose.

$\mathrm{Na}$ literatura, são escassos relatos de trabalhos com referência à resistência à antracnose em mudas de maracujazeiroamarelo sob condições de casa de vegetação, no entanto verificou-se que os graus de resistência obtidos para alguns genótipos, neste trabalho, são similares àqueles obtidos por Junqueira et al. (2003) e Sousa (2005). A reação de resistência de genótipos oriundos de retrocruzamentos com espécies selvagens, como: RC-3, PES-7 e PES-9, ou de cruzamento intraespecífico, como: o GA-2, Rubi gigante, foi também verificado por Junqueira et al. (2005) por avaliação em campo.

Independentemente dos parâmetros utilizados para avaliar a resistência dos genótipos ao fungo C. gloeosporioides, houve diferentes níveis de reações destes ao fungo, o que pode ser um indicativo de resistência horizontal do maracujazeiro à doença.

As diferenças nos níveis de resistência apresentados pelos genótipos de maracujazeiro ao fungo C. gloeosporioides, entre e dentro dos genótipos, podem ser atribuídas à presença de mecanismos de defesa diferentes, presentes na planta.

Quanto às folhas com sintomas de antracnose, a queda das mesmas pode ter ocorrido devido à reação de hipersensibilidade. De acordo com Medeiros et al. (2003), a reação de hipersensibilidade é um tipo de defesa bioquímica induzida como resposta ao ataque do patógeno à planta, e consiste em 
morte rápida de células do hospedeiro adjacentes ao local da penetração, privando o patógeno de nutrientes e impedindo sua propagação. Esses autores afirmam que algumas respostas bioquímicas de reação de hipersensibilidade se mostram semelhantes àquelas que ocorrem após injúria mecânica, senescência ou estresse.

TABELA 1 - Severidade média (nota), incidência (\%) e grau de resistência dos genótipos de maracujazeiro-amarelo ao fungo $C$. gloeosporioides (antracnose) nas 7 avaliações. Estação Biológica, FAV.

\begin{tabular}{|c|c|c|c|c|c|c|c|}
\hline Genótipos & Severidade & Incidência & $\begin{array}{c}\text { Média das } 7 \\
\text { avaliações }\end{array}$ & Genótipos & Severidade & Incidência & $\begin{array}{c}\text { Média das } 7 \\
\text { avaliações }\end{array}$ \\
\hline MAR 20-01 & 4,67 & $96,42-a-g$ & $\mathrm{AS}$ & MAR 20-41 & 4,57 & $97,02-a-j$ & $\mathrm{AS}$ \\
\hline MAR 20-03 & 4,98 & $97,01-a-f$ & AS & MAR 20-43 & 4,27 & $98,08-a b$ & AS \\
\hline MAR 20-04 & 4,61 & $96,18-a-g$ & AS & MAR 20-44 & 4,94 & $96,42-a-g$ & $\mathrm{AS}$ \\
\hline MAR 20-05 & 4,43 & $82,02-1$ & AS & MAR 20-45 & 4,76 & $96,42-a-g$ & AS \\
\hline MAR 20-06 & 4,30 & $97,02-a-f$ & AS & MAR 20-46 & 4,23 & $90,83-\mathrm{f}-\mathrm{j}$ & $\mathrm{AS}$ \\
\hline MAR 20-07 & 4,82 & $96,48-a-g$ & AS & MAR 20-47 & 4,99 & $96,90-a-f$ & AS \\
\hline MAR 20-08 & 5,17 & $98,21-a-d$ & AS & MAR 20-48 & 4,53 & $92,85-b-d$ & $\mathrm{AS}$ \\
\hline MAR 20-09 & 4,79 & $96,42-a-g$ & AS & MAR 20-49 & 4,10 & $92,14-c-j$ & $\mathrm{AS}$ \\
\hline MAR 20-11 & 4,14 & $83,56-\mathrm{k}-1$ & AS & MAR 20-50 & 4,26 & $97,02-a-f$ & AS \\
\hline MAR 20-13 & 5,09 & $98,80-\mathrm{ab}$ & AS & $20 / 205$ & 4,73 & $98,81-a b$ & $\mathrm{AS}$ \\
\hline MAR 20-14 & 4,25 & $98,57-a-c$ & AS & Am. Alongado & 4,90 & $96,42-a-g$ & $\mathrm{AS}$ \\
\hline MAR 20-15 & 4,65 & $91,05-e-j$ & AS & Am. Arredondado & 5,03 & $96,30-\mathrm{a}-\mathrm{g}$ & AS \\
\hline MAR 20-16 & 3,97 & 95,50 -a-e & $\mathrm{S}$ & AP-1 & 4,35 & $97,02-a-f$ & $\mathrm{AS}$ \\
\hline MAR 20-17 & 4,81 & $97,02-a-f$ & AS & AR-Z & 3,80 & $91,65-d-j$ & $\mathrm{~S}$ \\
\hline MAR 20-19 & 4,18 & $96,42-a-g$ & AS & AR-1 & 4,79 & $97,37-a-f$ & AS \\
\hline MAR 20-20 & 4,48 & $96,31-a-g$ & AS & EC-3-0 & 4,55 & $97,62-a-d$ & AS \\
\hline MAR 20-21 & 4,91 & $98,81-a b$ & AS & EC-L-7 & 5,19 & $97,14-a-f$ & AS \\
\hline MAR 20-22 & 4,35 & $96,42-a-g$ & AS & FB 100 & 4,66 & $96,30-a-g$ & AS \\
\hline MAR 20-23 & 4,82 & $99,22-a b$ & AS & YM 200 & 5,02 & $99,96-a$ & AS \\
\hline MAR 20-24 & 4,72 & $97,02-a-f$ & $\mathrm{AS}$ & GA-2 & 3,33 & 89,52 -h-k & $\mathrm{S}$ \\
\hline MAR 20-25 & 5,30 & $99,96-a$ & AS & GA2 X Rubi Híbr & 4,46 & $94,00-a-h$ & $\mathrm{AS}$ \\
\hline MAR 20-26 & 4,53 & $95,23-a-h$ & AS & Gigante Amarelo & 4,46 & $91,96-d-j$ & AS \\
\hline MAR 20-27 & 4,64 & $97,62-a-d$ & AS & Mar. Moranga & 4,45 & $86,90-\mathrm{i}-1$ & AS \\
\hline MAR 20-28 & 4,82 & $98,21-a-d$ & AS & PES-3 & 5,09 & $93,33-b-i$ & $\mathrm{AS}$ \\
\hline MAR 20-29 & 4,36 & $98,21-a-d$ & AS & PES-7 & 2,08 & $50,24-n$ & MR \\
\hline MAR 20-30 & 3,94 & $95,00-a-h$ & $\mathrm{~S}$ & PES-9 & 2,65 & $59,88-\mathrm{m}$ & MR \\
\hline MAR 20-31 & 4,53 & $97,26-a-f$ & AS & Prog 7 RC 3 & 3,01 & $61,78-\mathrm{m}$ & $\mathrm{S}$ \\
\hline MAR 20-32 & 4,40 & $97,02-a-f$ & AS & Redondão & 3,98 & $94,16-a-h$ & $\mathrm{~S}$ \\
\hline MAR 20-33 & 4,92 & $98,80-a b$ & AS & Roxo Aust. Poly. & 5,05 & $92,14-c-j$ & AS \\
\hline MAR 20-34 & 4,10 & $93,68-a-h$ & AS & Roxo Claro & 4,25 & $86,31-\mathrm{j}-1$ & $\mathrm{AS}$ \\
\hline MAR 20-35 & 4,26 & $91,67-d-j$ & $\mathrm{AS}$ & Rosa Claro & 4,48 & $96,90-a-f$ & AS \\
\hline MAR 20-36 & 4,49 & $97,02-a-f$ & AS & Rox Esc Along. & 4,86 & 97,61 -a-e & AS \\
\hline MAR 20-37 & 4,57 & $96,18-a-g$ & AS & Roxo médio & 5,35 & $93,46-a-i$ & $\mathrm{AS}$ \\
\hline MAR 20-38 & 4,87 & $92,10-c-j$ & AS & Roxo Médio Al. & 3,98 & $94,64-a-h$ & $\mathrm{~S}$ \\
\hline MAR 20-39 & 4,60 & $96,42-a-g$ & AS & Rubi Gigante & 3,70 & 89,99 -g-h & $\mathrm{S}$ \\
\hline MAR 20-40 & 4,67 & $99,28-a b$ & $\mathrm{AS}$ & Vermelhinho & 4,56 & $95,95-a-h$ & AS \\
\hline
\end{tabular}

* Médias seguidas por letras distintas diferem entre si, ao nível de significância de 5\%, pelo teste de Tukey MR = Moderadamente resistente

$\mathbf{S}=$ Suscetível

AS $=$ Altamente suscetível

CV $(\%)$ severidade $=16,100$

CV $(\%)$ incidência $=10,318$ 


\section{CONCLUSÕES}

1- Os genótipos demonstraram diferenças significativas na incidência de $C$. gloeosporioides ao longo das sete avaliações.

2- Os genótipos PES-7 e PES-9 foram classificados como moderadamente resistentes à antracnose, demonstrando potencialidade para programa de melhoramento, enquanto Redondão, Roxo Médio Alongado, MAR 20-16, MAR 20-30, AR2, GA 2, Rubi Gigante e o genótipo 7 RC3 foram classificados como suscetíveis, e os demais, como altamente suscetíveis.

3 - Verificou-se pequena variabilidade entre os genótipos estudados, porém, entre plantas de um mesmo genótipo, as variações foram mais acentuadas.

\section{REFERÊNCIAS}

ALMEIDA, L. C. C. Identificação específica de Colletotrichum caracterização da agressividade e efeito de indutores químicos no controle da antracnose em maracujá-amarelo. 2005. 79 f. Tese (Doutorado em Fitopatologia) - Universidade Federal Rural de Pernambuco, Recife, 2005.

AMORIM, L.; SALGADO, C. L. Diagnose. In: AMORIM FILHO, A.; KIMATI, H.; AMORIM, L. (Ed.). Manual de fitopatologia: princípios e conceitos. 3. ed. São Paulo: Agronômica Ceres, 1995. v. 1, p. 224-232.

ARX, J. A. von. Die Arten der Gattung Colletotrichum Corda. Phytopathologische Zeitschrift. Berlin, v. 29, n. 4, p. 413-468, 1957.

CUNHA, M. A. P. da; BARBOSA, L. V.; FARIA, G. A. Melhoramento genético. In: LIMA, A. de A.; CUNHA, M. A. P. da. Maracujá: produção e qualidade na passicultura. Cruz das Almas, BA: Embrapa Mandioca e Fruticultura, 2004. p. 68-93.

FISCHER, I. H.; KIMATI, H.; REZENDE, J. A. M. Doenças do maracujazeiro. In: KIMATI, H.; AMORIM, L.; REZENDE, J. A. M.; BERGAMIN FILHO, A.; CAMARGO, L. E. A. (Ed.). Manual de fitopatologia: doenças das plantas cultivadas. 4. ed. São Paulo: Ceres, 2005. v. 2, p. 466-474.

FRANCISCO NETO, E.; OLIVEIRA, J. C. de; CENTURION, M. A. P. C.; NAKAMURA, K. Influência da idade da folha, da luz e do método de inoculação na infecção de Passiflora por Colletotrichum gloeosporioides. Summa Phytopathologica, Botucatu, v. 21, n. 1, p. 25-29, 1995.

JUNQUEIRA, N. T. V.; ANJOS, J. R. N. dos; SILVA, A. P. O.; CHAVES, R. C.; GOMES, A. C. Reação as doenças e produtividade de onze cultivares de maracujá-azedo cultivados sem agrotóxicos. Pesquisa Agropecuária Brasileira, Brasília, v. 38, n. 8, p.10051010, ago. 2003.
JUNQUEIRA, N. T. V.; BRAGA, M. F.; FALEIRO, F. G.; PEIXOTO, J. R.; BERNACCI, L. C. Potencial de espécies silvestres de maracujazeiro como fonte de resistência a doenças. In: FALEIRO, F. G., JUQUEIRA, N. T. V., BRAGA, M. F. (Ed.). Maracujá germoplasma e melhoramento genético. Brasília, DF: Embrapa Cerrados, 2005. p. 80-108.

MEDEIROS, R. B. de; FERREIRA, M. A. S. V.; DIANESE, J. C. Mecanismos de agressão e defesa nas interações planta: patógeno. Brasília: Ed. da UnB, 2003.289 p.

MELETTI, L. M. M.; SOARES-SCOTT, M. D.; BERNACCI, L. C.; PASSOS, I. R. S. Melhoramento genético do maracujá: passado e futuro. In: FALEIRO, F. G. JUNQUEIRA, N. T. V., BRAGA, M. F. (Ed.). Maracujá germoplasma e melhoramento genético. Planaltina, DF: Embrapa Cerrados, 2005. p. 55-78.

MIRANDA, H. A. Incidência e severidade de Xanthomonas axonopodis pv. Passiflorae, Colletotrichum gloeosporioides, Septoria passiflorae, Cladosporium herbarum e Passion fruit Woodiness Virus em genótipos de maracujazeiro azedo cultivados no Distrito Federal. 2004. 87 f. Dissertação (Mestrado em Agronomia) - Universidade de Brasília, Brasília, DF, 2004.

SANTOS FILHO, H. P.; SANTOS, C. C. F. dos. Doenças causadas por fungos. In: SANTOS FILHO, H. P.; JUNQUEIRA, N. T. V. (Ed.). Frutas do Brasil: maracujá - fitossanidade. Brasília: Embrapa Informação Tecnológica, 2003. p. 12-21.

SANTOS FILHO, H. P., LARANJEIRA, F. F.; SANTOS, C. C. F. dos; BARBOSA, C. J. Doenças do maracujazeiro. In: LIMA, A. A.; CUNHA, M. A. P. da (Ed.). Maracujá: produção e qualidade na passicultura. Cruz das Almas, BA: Embrapa Mandioca e Fruticultura, 2004. p. 240-280.

SOUSA, M. A. F. Produtividade e reação a doenças em genótipos de maracujazeiro-azedo, cultivados no Distrito Federal. 2005. 138 f. Dissertação (Mestrado em Agronomia) - Universidade de Brasília, Brasília, DF, 2005.

SUTTON, B. C. The Coelomycetes fungi imperfecti with pycnidia acervuli and stromata. Kew: Commonwealth Mycological Institute, $1980.696 \mathrm{p}$.

SUTTON, B. C. The genus Glomerella and anamorph. In: BAILEY, J. A.; JEGER, M. J. Colletotrichum: biology, pathology and control. Wallingford: CAB International, $1992.388 \mathrm{p}$.

TODAFRUTA. Doenças causadas por fungos. Disponível em: $<$ h t t p : / / w w w c o m . b r t o d a f r u t a / mostra_conteudo.asp?conteudo $=\mathbf{6 3 9 3}>$. Acesso em: 19 jan. 2006.

ZONTA, E. P.; MACHADO, A. A. Sistema de análises estatísticas (SANEST) para microcomputadores. In: SIMPÓSIO DE ESTATÍSTICA APLICADA À EXPERIMENTAÇÃO, 1995, Piracicaba. Resumos... Campinas: Fundação Cargill, 1995. p. 1718. 